\author{
Marquette University \\ e-Publications@Marquette
}

6-1985

\title{
The Effects of Private Self-Consciousness and Perspective Taking on Satisfaction in Close Relationships.
}

Stephen L. Franzoi

Marquette University, stephen.franzoi@marquette.edu

Mark H. Davis

Indiana University

Richard D. Young

Indiana University

Follow this and additional works at: https://epublications.marquette.edu/psych_fac

Part of the Psychology Commons

\section{Recommended Citation}

Franzoi, Stephen L.; Davis, Mark H.; and Young, Richard D., "The Effects of Private Self-Consciousness and Perspective Taking on Satisfaction in Close Relationships." (1985). Psychology Faculty Research and Publications. 387.

https://epublications.marquette.edu/psych_fac/387 


\section{Marquette University}

\section{e-Publications@Marquette}

\section{Psychology Faculty Research and Publications/College of Arts and Sciences}

This paper is NOT THE PUBLISHED VERSION; but the author's final, peer-reviewed manuscript. The published version may be accessed by following the link in the citation below.

Journal of Personality and Social Psychology, Vol. 48, No. 6 (1985): 1584-1594. DOI. This article is (C) American Psychological Association and permission has been granted for this version to appear in ePublications@Marquette. American Psychological Association does not grant permission for this article to be further copied/distributed or hosted elsewhere without the express permission from American Psychological Association

\section{The Effects of Private Self-Consciousness and Perspective Taking on Satisfaction in Close Relationships}

By: Stephen L. Franzoi Indiana University; Department of Psychology, Marquette University; Mark H. Davis Indiana University; Eastern Illinois University

Richard D. Young

Indiana University

Acknowledgement: Work on this study was supported by funds provided by the Post-Doctoral Program in Social Psychology, Grant PHS T32 MH 14588-04, and by the Post-Doctoral Program in Measurement, Grant PHS T32 15789-02, Indiana University, Bloomington.

We thank Sheila Skok for her help in data collection.

The impact that personality characteristics have on the nature and quality of social relationships has recently received increased research attention. Two personal characteristics-both reflecting an awareness of and sensitivity to affective and motivational states-seem particularly likely to influence the quality of close 
relationships. These two characteristics are self-awareness (or self-consciousness) and social perspective taking (or role taking). Self-awareness usually refers to the attempt to understand one's own internal states; perspective taking refers to the attempt to understand the point of view of others. Although most adults are capable of both, research has demonstrated that there are reliable individual differences in the degree to which people habitually engage in these psychological states (Davis, 1980; Fenigstein, Scheier, \& Buss, 1975). We extend the scope of recent studies in which self-awareness and perspective taking have been used as predictors of social competence or adjustment: We analyzed their influence on the satisfaction individuals experience in monogamous, heterosexual relationships.

The specific type of self-awareness of interest in this study, namely private self-consciousness, refers to the dispositional tendency to focus attention on private and covert aspects of oneself. On the basis of a number of studies (e.g., Bernstein \& Davis, 1982; Franzoi, 1983; Scheier, Buss, \& Buss, 1978; Turner, 1978a), one can conclude that high private self-consciousness is associated with a more detailed and accurate knowledge of internal selfaspects. The measure of perspective taking used here, developed by Davis $(1980,1983)$, taps the tendency of an individual to entertain the psychological point of view of other people (i.e., to put aside temporarily one's own perspective and attempt to adopt that of another). This measure of perspective taking has been found to be predictive of accuracy in judging others (Bernstein \& Davis, 1982) and of success in a bargaining simulation (Neale \& Bazerman, 1983), and to be consistently associated with a number of measures theoretically relevant to the perspective taking construct (Davis, 1983).

\section{Private Self-Consciousness and Couples' Satisfaction}

Consider how private self-consciousness might affect relationship satisfaction through the communication of one's own behavioral tendencies and emotions. Considerable evidence currently supports the view that the disclosure of intimate self-information within a close relationship has a beneficial effect on satisfaction with that relationship and on subjective feelings of well-being generally. For example, Levinger and Senn (1967) and Burke, Weir, and Harrison (1976) reported greater happiness in close relationships characterized by greater self-disclosure between partners. Recently, a number of investigators have also provided evidence of a link between selfdisclosure and the subjective experience of loneliness, the dominant finding being that greater disclosure leads to fewer feelings of social isolation and alienation (e.g., Berg \& Peplau, 1982; Chelune, Sultan, \& Williams, 1980; Franzoi \& Davis, 1985; Solano, Batten, \& Parish, 1982). From these studies, it appears that intimate self-disclosure can influence the quality of social relationships.

In an attempt to account for individual differences in self-disclosure tendencies and its relation to social satisfaction, Franzoi and Davis (1985) argued that individuals who habitually attend to their own private thoughts and feelings should be more likely to engage in intimate self-disclosure than those who do not normally attend to this psychological state. Their reasoning is that the content of private self-awareness-emotions, thoughts, aspirations, and doubts -is typical material for intimate self-disclosure, and persons possessing more detailed and accurate self-knowledge as a result of self-attention to thoughts and feelings should be better equipped to disclose to others. The results of their causal analysis of adolescent loneliness (Franzoi \& Davis, 1985) revealed exactly this pattern: Greater private self-consciousness was linked with more intimate self-disclosure to peers and, furthermore, greater peer disclosure was linked to increased social satisfaction (i.e., less loneliness). The clear implication of these results is that private self-consciousness influences tendencies to engage in intimate self-disclosure, which in turn has an impact on the self-disclosers' feelings of social satisfaction.

Does self-disclosure have an equal impact on the satisfaction experienced by partners receiving personal information? Derlega and Grzelak (1979), in a functional analysis of self-disclosure, suggested possible benefits for givers and receivers relevant to our investigation. For receivers, self-disclosure often provides information about the disclosers that helps in better understanding their behavior in the relationship. Furthermore, being chosen 
as the target for self-disclosure may be rewarding itself, indicating a sense of trust. For givers, on the other hand, self-disclosure provides the opportunity to increase personal clarification: Self-disclosing may provide the necessary time to clarify one's needs and desires to oneself. Although personal clarification may occur without feedback from the one who is disclosed to, self-disclosing also, according to Derlega and Grzelak, opens the door for social validation of one's perceptions and beliefs. Partners may help individuals to define the appropriateness and correctness of their attitudes, beliefs, and values during disclosure and thus help them to decide on courses of action in dealing with various situations. Derlega and Grzelak (1979) further suggested that self-disclosing may be a self-rewarding activity in its own right, satisfying expressive needs of the individual. From this overview of potential self-disclosure benefits to couple's feelings of satisfaction, we conclude that although there may be more reasons to expect self-disclosure to influence the discloser's satisfaction than the receiver's, we can make no specific predictions concerning differences in this study.

\section{Perspective Taking and Couples' Satisfaction}

In contrast to the expected influence of private self-consciousness on relationship satisfaction, the influence of perspective taking is less likely to be a function of the disclosure of self-information; Franzoi and Davis (1985), in fact, found only a marginal association between individuals' level of perspective taking and their tendencies to self-disclose. Instead, perspective taking should facilitate social relationships in a different fashion. Generally speaking, the theoretical view of perspective taking has been that it is a fundamental social skill necessary for the formation of normal social attachments (e.g., Mead, 1934; Piaget, 1932). More specifically, symbolic interactionists (e.g., Turner, 1978b) have seen it as crucial for smooth social relationships because it permits the anticipation of others' behavior; such anticipation in turn allows one to take others' reactions into account before one's own behavior occurs. Recently, Davis (1983) reported that low perspective taking among college students was consistently (though modestly) associated with a host of characteristics indicating interpersonal dysfunction, including shyness, social anxiety, and an arrogant, inconsiderate social style. Thus theory and evidence both suggest that perspective takers, by virtue of their better social skills and less abrasive social style, experience better, smoother social relationships. In summary, therefore, there seems ample reason to expect a link between perspective taking and relationship satisfaction, and little reason to expect that this link is mediated by a willingness to self-disclose.

To some, it might seem counterintuitive to expect no relation between a fundamental social skill such as perspective taking and an important social behavior such as self-disclosure. In particular, this may seem surprising because perspective taking is associated with a tendency to elicit disclosure from others (Miller, Berg, \& Archer, 1983). Should this not lead to a link between perspective taking and disclosure? This compelling and apparently logical reasoning led to exactly such a prediction in Franzoi and Davis's (1985) investigation, and it was not supported: No significant association between perspective taking and self-disclosure was found. The post hoc explanation of those results was that the logical chain leading to the prediction (perspective taking elicits disclosure from others, which in turn leads to reciprocal disclosure) was not strong enough; break-downs anywhere in the inferential chain would eliminate any observed direct influence of perspective taking on selfdisclosure. As a result, we predicted no such direct influence in this study.

Taken as a whole, the current literature suggests an indirect relation between private self-consciousness and couple satisfaction. In our study we predicted that private self-consciousness would be positively related to selfdisclosure. In turn, we also predicted that there would be a positive relation between self-disclosure and happiness in the relationship. In contrast, theory and research both suggest that any influence of perspective taking on relationship satisfaction is probably not due to self-disclosure tendencies, but to other factors, such as an accurate understanding of the partner, a willingness to listen, or a generally tactful and accommodating 
social style (Davis, 1983). On the basis of this expectation, we predicted that the influence of perspective taking on happiness would not be mediated by self-disclosure with partner.

\section{Method}

\section{Subjects}

The sample consisted of 131 heterosexual student couples at Indiana University. Of these couples, 30 (23\%) were married or engaged; the rest reported that they were dating one another exclusively. The age of the female subjects in this sample ranged from 17 to 30 years, with a mean age of 20; male subjects ranged in age from 17 to 32 years, with a mean of 21 . The length of time that these couples had been dating or married was, for a student sample, considerable. Only $6 \%$ of the couples had been together for less than 2 months; an additional 18\% reported being together from 3 to 6 months, and 17\% indicated relationships from 6 to 12 months old. Over a quarter of the sample (27\%) reported being in the relationship between 13 and 24 months, and nearly a third (32\%) indicated that they had been together for over 2 years.

\section{Procedure}

Subjects were recruited from introductory psychology and sociology classes and qualified for the study if they were currently involved in an intimate and monogamous heterosexual relationship. Because in most cases both members of the relationship were not enrolled in the targeted classes, it was necessary to have those who were enrolled enlist their partners in the study. Enrolled subjects completed and returned the Relationship Questionnaire during a 15-min period during the normal class hour, and were then given a blank Relationship Questionnaire for their partners to complete in private. Subjects who completed the questionnaires in class placed their social security numbers on both forms so that proper identification could be made once their partners had responded to the survey. On receipt of the non-enrolled subjects' completed questionnaires (returned through campus mail or by non-enrolled subjects' partners), couples' responses were matched and tabulated.

\section{Relationship Questionnaire}

On the questionnaire, subjects were asked to provide information concerning their sex, age, marital status, and length of current relationship. The two personality variables of interest were private self-consciousness and perspective-taking tendencies. Private self-consciousness was measured via the 10-item private selfconsciousness subscale of the Self-Consciousness Scale (Fenigstein et al., 1975); perspective taking was measured via the 7-item perspective-taking subscale of the Interpersonal Reactivity Index (IRI; Davis, 1980). The private self-consciousness subscale has been widely used in recent years, and higher scores on this measure have been linked to a number of theoretically relevant constructs, such as more detailed self-knowledge (Franzoi, 1983; Turner, 1978a) and greater correspondence between self-report and behavior (e.g., Scheier et al., 1978). The perspective-taking (PT) subscale was developed more recently, and constitutes one portion of a multidimensional measure of empathy (the IRI). Davis (1980), in describing the development of this measure, reported that the PT subscale has adequate internal reliability ( $\alpha=.75$ for male subjects and .78 for female subjects); recent investigations (e.g., Bernstein \& Davis, 1982; Davis, 1983; Miller et al., 1983) provided evidence that it indeed measures the individual's tendency to spontaneously adopt the psychological point of view of others.

Because of time constraints in questionnaire responding, degree of current self-disclosure to one's partner was measured via four items ("We discuss things that are important to me in my life"; "We discuss things that I like and dislike about myself"; "We discuss my worst fears"; "We discuss things I have done which I feel guilty about") selected from the Self-Disclosure Index (SDI; Miller et al., 1983). Using a 5-point scale from 1 (extremely uncharacteristic) to 5 (extremely characteristic), subjects indicated how characteristic each statement was of their relationship. Miller et al.'s (1983) factor analysis of the full 10-item SDI revealed that all items loaded on a single 
factor for both male and female subjects. The internal consistency of the SDI was high (Cronbach's $\alpha=.87$ for men, .86 for women), and the index was substantially correlated with the Jourard (1971) Self-Disclosure Questionnaire ( $r=.49$ for men, .65 for women). Subjects scoring high on the SDI have been found to report more actual disclosure to others than subjects scoring low on the index (Miller et al., 1983). In a previous study, Franzoi and Davis (1985), using the 4-item shortened SDI, found that correlations between the long and short form were extremely high ( $r=.94$ for male subjects, .89 for female subjects), indicating that the shortened Self-Disclosure Index is an adequate substitute for the longer SDI.

We assessed degree of satisfaction or harmony in the relationship by using 9 slightly modified items from the Marital Adjustment Test (Locke, 1951). Eight of these items were modified so that they conformed to a standard 5 -item Likert scaling procedure and applied to both married and nonmarried couples. Four items dealt with degree of agreement over issues of importance in the relationship ("Do you and your partner agree on amount of time spent together?", "Do you and your partner agree on friends?", "Do you and your partner agree on aims, goals, and things believed important in life?", and "Do you and your partner agree on handling finances?"); responses range from always agree to always disagree. The other four items dealt directly with degree of relationship happiness ("How frequently do you and your partner get on each other's nerves?", "Have you ever wished you were not going with your partner?", "How happy would you rate your relationship?", and "How satisfying to you is your relationship with your partner?"); responses range from almost always, very unhappy, or very unsatisfying to almost never, very happy, or very satisfying. Because half the items dealt with degree of agreement over relationship issues and half dealt with relationship happiness, we performed principal components analyses of the data to determine whether the items loaded on a single factor. Separate factor analyses of the male and female responses resulted in single-factor solutions for both sexes (eigenvalue criterion $>1.00)$. When male and female responses were combined, a single-factor solution again resulted. On the basis of these analyses, it appears that the eight items derived from the Marital Adjustment Test are measures of a single construct dealing with degree of harmony or satisfaction in a close relationship. Thus responses to these eight items were summed for each subject to produce a single measure of satisfaction.

In addition to the measure of couple satisfaction, a single item concerning conflict resolution within the relationship was included ("When disagreements between you and your partner arise, they generally result in: (a) You giving in (b) Partner giving in (c) Neither giving in (d) Agreement by mutual give-and-take"). Because this item did not entail an ordinal response scale, it was not included in the satisfaction index.

\section{Results}

\section{Strategy of the Analyses}

As indicated earlier, we were interested in examining the effects of personality characteristics on relationship satisfaction and, in particular, in examining the degree to which these effects were mediated by self-disclosure. Because of this, many of the major analyses took the form of hierarchical regression analyses, in which predictor variables are entered into the regression equation in a predetermined order (Cohen \& Cohen, 1975). Because this strategy allows the assessment of any given predictor's impact above and beyond the effect of variables entered into the equation earlier, it allowed us to estimate the degree to which a predictor variable's influence was mediated by some intervening variable.

The initial step in this analysis consisted of a pair of regression analyses in which we used the hierarchical strategy. In these two analyses, the criterion variables were the self-disclosure indexes reported by male and female subjects, and in each one there were five predictor variables. On the first step of each analysis, length of the relationship was entered; on the second step the scores of male and female subjects on the perspectivetaking and private self-consciousness scales were entered. The results of these analyses appear in Table 1. 
Table 1

Influence of Personality Characteristics and

Relationship Length on Male and

Female Self-Disclosure

\begin{tabular}{|c|c|c|c|c|}
\hline \multirow[b]{2}{*}{ Predictors } & \multicolumn{2}{|c|}{$\begin{array}{l}\text { Male self- } \\
\text { disclosure }\end{array}$} & \multicolumn{2}{|c|}{$\begin{array}{c}\text { Female self- } \\
\text { disclosure }\end{array}$} \\
\hline & $r$ & $\beta$ & $r$ & $\beta$ \\
\hline $\begin{array}{l}\text { Step 1 } \\
\text { Length of } \\
\text { relationship }\end{array}$ & .04 & .04 & .14 & .14 \\
\hline $\begin{array}{l}\text { Step } 2 \\
\text { Male private } \\
\text { self-consciousness } \\
\text { Male perspective } \\
\text { taking } \\
\text { Female private } \\
\text { self-consciousness } \\
\text { Female perspective } \\
\text { taking }\end{array}$ & $\begin{array}{r}.36 \\
.21 \\
-.05 \\
.09\end{array}$ & $\begin{array}{c}.35 * * * \\
.12 \\
-.14 \\
.08\end{array}$ & $\begin{array}{l}.20 \\
.05 \\
.27 \\
.11\end{array}$ & $\begin{array}{c}.17^{*} \\
.02 \\
.24 * * \\
-.01\end{array}$ \\
\hline
\end{tabular}

Note. For male self-disclosure, $F(5,113)=4.54, R=.41$, $R^{2}=.17$; for female self-disclosure, $F(5,113)=3.13$, $R=.35, R^{2}=.12$.

${ }^{*} p<.10 .^{* *} p<.05{ }^{* * *} p<.01$.

Influence of Personality Characteristics and Relationship Length on Male and Female Self-Disclosure

\section{Personality, Self-Disclosure, and Relationship Satisfaction}

The most obvious and important finding is that the self-disclosure of both male and female subjects is significantly affected by their level of private self-consciousness. As predicted, habitual attention to private thoughts and feelings was significantly associated with greater self-disclosure to one's romantic partner. This relation between private self-consciousness and self-disclosure is consistent with findings obtained by Franzoi and Davis (1985) and by Miller et al. (1983). As expected, no significant relation was discovered between levels of interpersonal perspective taking and disclosure. There was also a marginally significant positive association between male subjects' level of private self-consciousness and female subjects' reported disclosure.

After an examination of the direct effects of personality variables on self-disclosure, the next step was to examine a pair of related questions. First, does self-disclosure have the predicted facilitating effect on relationship satisfaction? Second, do either of the personality variables influence satisfaction above and beyond the influence exerted through self-disclosure? Again, we addressed both questions through the use of hierarchical regression analyses. In the two analyses to be reported, the criterion variables were the reported satisfaction of male and female subjects. In each analysis, the first variable entered was the length of the relationship. By introducing length of relationship first, the effects of the later variables represent their unique contribution to satisfaction, independent of relationship length. On the second step, the two self-disclosure indexes (i.e., male and female self-disclosure) were entered. Finally, the four personality characteristics were entered in the third and final step of the regression equation. As before, any influence of these variables on satisfaction represented a contribution independent of the mediating effects of self-disclosure. The results of these analyses are displayed in Table 2. 
Table 2

Influence of Self-Disclosure, Personality

Characteristics, and Relationship Length on Male

and Female Satisfaction With the Relationship

\begin{tabular}{|c|c|c|c|c|}
\hline \multirow[b]{2}{*}{ Predictors } & \multicolumn{2}{|c|}{$\begin{array}{c}\text { Male } \\
\text { satisfaction }\end{array}$} & \multicolumn{2}{|c|}{$\begin{array}{c}\text { Female } \\
\text { satisfaction }\end{array}$} \\
\hline & $r$ & $\beta$ & $r$ & $\beta$ \\
\hline $\begin{array}{l}\text { Step 1 } \\
\text { Length of } \\
\quad \text { relationship }\end{array}$ & -.17 & $-.17^{*}$ & -.20 & $-.20^{* *}$ \\
\hline $\begin{array}{l}\text { Step } 2 \\
\text { Male self-disclosure } \\
\text { Female self- } \\
\text { disclosure }\end{array}$ & $\begin{array}{l}.26 \\
.10\end{array}$ & $\begin{array}{l}.25^{* * *} \\
.08\end{array}$ & $\begin{array}{l}.07 \\
.20\end{array}$ & $\begin{array}{l}.04 \\
.23^{* *}\end{array}$ \\
\hline $\begin{array}{l}\text { Step } 3 \\
\text { Male private } \\
\text { self-consciousness } \\
\text { Male perspective } \\
\text { taking } \\
\text { Female private } \\
\text { self-consciousness } \\
\text { Female perspective } \\
\text { taking }\end{array}$ & $\begin{array}{r}.17 \\
.28 \\
-.05 \\
.24\end{array}$ & $\begin{array}{c}.00 \\
.22^{* *} \\
-.16^{*} \\
.25^{* * *}\end{array}$ & $\begin{array}{l}.20 \\
.13 \\
.05\end{array}$ & $\begin{array}{c}.12 \\
.09 \\
-.11 \\
.20^{* *}\end{array}$ \\
\hline
\end{tabular}

Note. For male satisfaction, $F(7,111)=4.36, R=.46$, $R^{2}=.22$; for female satisfaction, $F(7,111)=2.91, R=$ $.39, R^{2}=.16$.

${ }^{*} p<.10 .{ }^{* *} p<.05 .^{* * *} p<.01$.

Influence of Self-Disclosure, Personality Characteristics, and Relationship Length on Male and Female Satisfaction With the Relationship

Consistent with previous research (e.g., Burr, 1970; Glass \& Wright, 1977; Luckey, 1966), there was a tendency for relationship length to be inversely related to satisfaction. This tendency for longer relationships to be characterized by less satisfaction was statistically significant for female subjects and marginally significant for male subjects. At the second step, the two self-disclosure variables were entered as predictors of satisfaction. For both male and female subjects, greater self-disclosing was significantly associated with greater discloser satisfaction, but was not significantly associated with greater satisfaction for the recipient of the disclosure interaction.

On the third step, the four individual characteristics were entered as predictors. Only perspective taking was significantly and directly related to satisfaction of either partner. Female perspective taking was associated with higher levels of both male and female satisfaction, and male perspective taking was associated with greater male satisfaction. Thus the perspective-taking tendency of the female member of the couple had the broadest influence on the couple's satisfaction. The only other result was an unexpected marginal effect of female selfconsciousness on male satisfaction, with greater self-consciousness scores associated with less satisfaction.

When these results are taken in conjunction with the results in Table 1, a pattern emerges. For both male and female subjects, individual differences in level of private self-consciousness appears to exert a predictable significant influence on their own tendencies to self-disclose, and their degree of self-disclosure in turn 
influences their satisfaction with the relationship. Thus an indirect influence of private self-consciousness on satisfaction can be clearly seen. Furthermore, when the effects of disclosure on satisfaction are controlled (Table 2), no positive effect of private self-consciousness on satisfaction is apparent, which supports the view that any effect of self-consciousness on satisfaction is due to its impact on disclosure. In contrast, perspective taking exerts no influence on self-disclosure, and yet it significantly affects satisfaction, even when the effects of disclosure on satisfaction are controlled. Thus perspective taking has an effect on satisfaction independent of the salutary effects of self-disclosure.

\section{Perspective Taking and Conflict Resolution}

If it is not through self-disclosure, then in what fashion does perspective taking produce greater relationship satisfaction? According to the rationale advanced earlier, the influence of perspective taking on satisfaction should be largely due to its impact on social style; that is, perspective taking should be associated with a considerate, tactful style, characterized by a greater appreciation of the wishes, desires, and legitimate interests of others. When, for instance, the wishes of two persons come into conflict, perspective taking should serve to reduce potential conflict by fostering in the participants a better understanding of the different viewpoints. In particular, social perspective taking in these situations may lead to a greater willingness of people to engage in a mutual give-and-take with those holding conflicting views; that is, because one can appreciate the reasons for a conflicting point of view, one may be more likely to attempt an accommodation with (and less likely to seek a confrontation between) the disagreeing sides.

The one item from the Relationship Questionnaire that concerned how couples resolve their conflicts was analyzed to determine its relation to perspective taking and satisfaction. However, in order to use this item as a possible mediator of relationship satisfaction, responses were recoded in the following manner: If both members of a couple reported mutual give-and-take in settling their disputes, the couple was assigned a value of 1.0; if both members reported some other mode of resolution, the couple was assigned a value of 0.0; if one member reported mutual give-and-take and the other did not, a value of 0.5 was assigned. Thus couples were given higher scores as they reported higher levels of mutual give-and-take.

To test the notion that a couple's mode of conflict resolution mediates the impact of perspective taking on relationship satisfaction, we performed a series of analyses similar to those reported earlier. In the first set of analyses, whose results appear in Table 3, we used the four personality variables and relationship length as predictors of conflict resolution. Male perspective taking was clearly related to mode of conflict resolution, with greater perspective taking associated with more mutual give-and-take. The relationship for female perspective taking was in the predicted direction, but was not significant. 
Table 3

Influence of Personality Characteristics and

Relationship Length on Couples' Reported Mode

of Conflict Resolution

\begin{tabular}{llc}
\hline & \multicolumn{2}{c}{ Conflict resolution } \\
\cline { 2 - 3 } \multicolumn{1}{c}{ Predictor } & $r$ & $\beta$ \\
\hline $\begin{array}{l}\text { Step 1 } \\
\text { Length of } \\
\text { relationship }\end{array}$ & -.17 & $-.17^{*}$ \\
$\begin{array}{l}\text { Step 2 } \\
\text { Male private } \\
\quad \text { self-consciousness } \\
\begin{array}{c}\text { Male perspective } \\
\text { taking }\end{array}\end{array}$ & .10 & .00 \\
$\begin{array}{l}\text { Female private } \\
\text { self-consciousness }\end{array}$ & .25 & $.24 * *$ \\
$\begin{array}{c}\text { Female perspective } \\
\text { taking }\end{array}$ & .07 & .02 \\
\hline
\end{tabular}

Note. For conflict resolution, $F(5,113)=3.12, R=.35$,

$R^{2}=.12$.

$* p<.10 . * * p<.01$.

Influence of Personality Characteristics and Relationship Length on Couples' Reported Mode of Conflict Resolution

In Table 4, the results of the final hierarchical regression analyses are presented. In these analyses, the criterion variables were male and female satisfaction, and the predictor variables were as follows: on the first step, length of relationship; on the second, male self-disclosure, female self-disclosure, and the conflict resolution variable; and on the third, the four personality variables. As the table illustrates, longer relationships were generally characterized by less satisfaction; the relationship between length and relationship satisfaction achieved significance for female subjects. At the second step, male disclosure was significantly related to male satisfaction, and female disclosure was significantly related to female satisfaction. An important finding was that greater levels of mutual give-and-take in the resolution of conflict were strongly associated with greater satisfaction for both males and females. Finally, although the earlier effects of perspective taking on satisfaction (Table 2) were somewhat weakened by the inclusion of the conflict resolution variable, they were still apparent. Female perspective taking still influenced both male and female satisfaction, although the effect on female satisfaction was now of borderline significance. Similarly, the effect of male perspective taking on male satisfaction, which had previously reached conventional significance levels, was now only marginal. Thus although the evidence here somewhat supports the notion of a causal path from perspective taking through conflict resolution to satisfaction, it is clear that the conflict resolution variable in this study does not completely account for the influence of perspective taking on satisfaction. 
Table 4

Influence of Self-Disclosure, Conflict Resolution,

Personality Characteristics, and Relationship

Length on Male and Female Satisfaction With

the Relationship

\begin{tabular}{|c|c|c|c|c|}
\hline \multirow[b]{2}{*}{ Predictors } & \multicolumn{2}{|c|}{$\begin{array}{c}\text { Male } \\
\text { satisfaction }\end{array}$} & \multicolumn{2}{|c|}{$\begin{array}{c}\text { Female } \\
\text { satisfaction }\end{array}$} \\
\hline & $r$ & $\beta$ & $r$ & $\beta$ \\
\hline $\begin{array}{l}\text { Step 1 } \\
\text { Length of } \\
\text { relationship }\end{array}$ & -.17 & $-.17^{*}$ & -.20 & $-.20 * *$ \\
\hline $\begin{array}{l}\text { Step } 2 \\
\text { Conflict resolution } \\
\text { Male self-disclosure } \\
\text { Female self- } \\
\text { disclosure }\end{array}$ & $\begin{array}{l}.37 \\
.26\end{array}$ & $\begin{array}{l}.31^{* * * *} \\
.21^{* * *} \\
.03\end{array}$ & $\begin{array}{l}.37 \\
.07\end{array}$ & $\begin{array}{l}.31 * * * \\
-.01 \\
.18^{* * *}\end{array}$ \\
\hline $\begin{array}{l}\text { Step } 3 \\
\text { Male private } \\
\text { self-consciousness } \\
\text { Male perspective } \\
\text { taking } \\
\text { Female private } \\
\text { self-consciousness } \\
\text { Female perspective } \\
\text { taking }\end{array}$ & $\begin{array}{r}.28 \\
-.05\end{array}$ & $\begin{array}{c}.16^{*} \\
-.16^{*} \\
.21^{* *}\end{array}$ & $\begin{array}{l}.13 \\
.05\end{array}$ & $\begin{array}{c}.02 \\
-.11 \\
.16^{*}\end{array}$ \\
\hline
\end{tabular}

Note. For male satisfaction, $F(8,110)=5.02, R=.52$, $R^{2}=.27$; for female satisfaction, $F(8,110)=3.96, R=$ $.47, R^{2}=.22$.

${ }^{*} p<.10 .{ }^{* *} p<.05 .^{* * *} p<.01$.

Influence of Self-Disclosure, Conflict Resolution, Personality Characteristics, and Relationship Length on Male and Female Satisfaction With the Relationship

\section{Discussion}

Two expectations guided us in this research. First, we anticipated that a chronic tendency towards introspection would increase satisfaction with intimate relationships because of the greater self-disclosure resulting from that heightened self-awareness. Second, we expected that a chronic tendency to adopt the psychological point of view of others would help foster relationship satisfaction, independently of any influence of self-disclosure. Both expectations were confirmed. Scores on the private self-consciousness scale were predictive of reported selfdisclosure, and self-disclosure scores were predictive of satisfaction with the intimate relationship. A more important finding was that no effect of self-consciousness on happiness remained after the influence of selfdisclosure was removed. In contrast, perspective taking scores were significantly related to satisfaction after disclosure was controlled, and were in fact unrelated to disclosure at all.

\section{Private Self-Consciousness and Close Relationships}

The implications of these results for our understanding of self-consciousness are considerable and suggest intriguing theoretical possibilities. Most important, they indicate that high private self-conscious individuals' greater satisfaction in close relationships is not simply due to their being more in touch with their private thoughts and feelings, but results from their increased tendency to share these thoughts and feelings with loved 
ones. This finding, in concert with the Franzoi and Davis (1985) results, suggests not that habitual self-attention leads to social isolation, but rather that it can facilitate an intimate social sharing that reduces loneliness and increases satisfaction with social relationships.

Because disclosing one's "private side" to others is believed to result in greater self-understanding (Jourard, 1971), these findings may further explain self-concept differences in high and low self-conscious individuals. Researchers in past studies have found that individuals high in private self-consciousness are more aware of their behavioral tendencies (e.g., Bernstein \& Davis, 1982; Franzoi, 1983; Scheier et al., 1978) and have more articulated self-concepts (Franzoi, 1983; Turner, 1978a) than do low private self-conscious individuals. This more knowledgeable and articulated self-understanding not only may be due to a heightened attention to private selfaspects, but also may be a result of a greater willingness to discuss these private matters with intimate others. By disclosing to others, individuals not only reduce the mystery surrounding their actions, but they also put themselves in a position to receive feedback concerning the veridical nature of their private inner thoughts and feelings. In this manner, individuals' own self-understanding can be compared with friends' and lovers' understanding of them, resulting in a greater likelihood that inaccuracies or misperceptions will be corrected. Thus greater knowledge of one's own, often private, nature may be partly due to a tendency to share this side of oneself with others.

An important issue raised but not settled by our findings concerns the possible motivational differences accounting for the relation between self-consciousness and self-disclosure. Because private self-awareness, by definition, involves attention to private self-information, a willingness to disclose this side of oneself to another may imply a desire to reveal one's private side, to let others know who one "really is" behind the often superficial self-presentations of everyday life. High private self-conscious individuals may disclose more to their friends and to their romantic partners not only because they have more private self-information available, but also because it may be more important for them to share these internal, nonvisible aspects of themselves with others. High private self-conscious individuals may be particularly appropriate of Derlega and Grzelak's (1979) description of those who self-disclose more because they have stronger needs for expression and self-validation. Conversely, underlying the low private self-conscious individuals' relative lack of self-disclosure may be a general reluctance to engage in activities in which personal, possibly intense feelings are felt and expressed. Results of a recent study (Franzoi \& Brewer, 1984) concerning the experience of daily self-awareness by high and low selfconscious individuals support this reasoning. Subjects low, in contrast to those high, in private selfconsciousness avoided private self-awareness when it was unpleasant. It is possible that low self-conscious individuals may not attend to their private self-aspects for the same reason that they do not discuss personal, intimate matters with friends and lovers (i.e., a reluctance to explore and reveal hidden, and perhaps unpleasant, personal qualities). By avoiding self-disclosure, low self-conscious individuals may be closing off another possible way to learn more about themselves.

Regarding the relation between self-disclosure and relationship satisfaction, we found evidence emphasizing the influence that self-disclosure has on the self-discloser's feelings of relationship satisfaction. These findings are consistent with the perspective that revealing one's "private self" to others fulfills important psychological needs of the discloser (Derlega \& Grzelak, 1979; Jourard, 1971). Although self-disclosure increased the discloser's satisfaction, it had little impact on the recipients' feelings of satisfaction in the relationship. Together, these findings suggest that revealing private self-aspects to one's partner is a more important factor influencing satisfaction than is listening to similar disclosure from one's partner.

\section{Perspective Taking and Close Relationships}

Conclusions regarding the perspective-taking results are less clearcut than for the self-consciousness findings, because it is not possible to so precisely identify the mechanism by which perspective taking leads to 
statisfaction. The results of the regression analyses in which we controlled for mode of conflict resolution suggest that at least some of the influence that perspective taking has on relationship satisfaction is due to a more democratic means of resolving conflict, although this cannot account for the entire effect. One promising hypothesis that generated from symbolic interaction theory and is consistent with these results is that the influence of perspective taking on satisfaction may be largely rooted in the avoidance of interpersonal friction, either through explicit settling of disputes, such as in this investigation, or through more subtle adjustments that occurred before overt conflict. In other words, perspective taking may enhance relationship satisfaction largely by eliminating some of the friction inherent in all social intercourse. Thus private self-consciousness enhances relationships by adding "positives" to the relationship (by helping provide a deeper and clearer knowledge of one's private self-aspects), whereas perspective taking aids the relationship by removing "negatives" (by reducing some of the tension produced by the psychological proximity of two different points of view).

As expected, self-disclosure played no mediating role in the impact of perspective taking on satisfaction. Although this finding does not support the hypothesis derived from Miller et al.'s (1983) study that high perspective takers should elicit intimate self-disclosure, it is consistent with Franzoi and Davis's (1985) analysis of factors influencing disclosure and social satisfaction (i.e., loneliness). Thus on the basis of our findings and the Franzoi and Davis (1985) results, it appears that a direct link between perspective taking and self-disclosure (both giving and receiving) has only surface plausibility.

An intriguing question concerns the finding that female perspective taking affects male satisfaction, whereas male perspective taking has no impact on female satisfaction. This is surprising, because there would seem to be no a priori reason for the tactful, considerate behavior of men to be unrelated to female satisfaction. However, one possible explanation for this finding may be found in the notion that men and women usually play different, largely complementary roles in romantic or family relationships. Parsons and Bales (1955) characterized the differing roles with the terms expressive and instrumental. Expressive roles, usually assigned to women, involve attending to the needs - particularly the emotional needs - of the family, including the maintenance of a harmonious social atmosphere among family members. Nurturant, emotional characteristics are particularly valuable in fulfilling this role. In contrast, the instrumental role, usually assigned to men, deals largely with providing for the family's economic welfare. Characteristics such as independence and self-reliance are more important for fulfilling this role.

Within this theoretical framework, it is possible to view perspective taking as being role relevant to the expressive role but not to the instrumental role; that is, a tendency to appreciate and understand the feelings and needs of others is of greater utility for successful role enactment if the role is primarily concerned with smooth and harmonious social relationships. It is less useful outside of such a context. If one assumes that women, even in today's society, still are predominantly fulfilling the expressive role in relationships, then perspective taking for women may be a particularly potent predictor of successful role performance, and might therefore lead to more satisfaction for both partners in the relationship. Although this role-relevant explanation of the data seems plausible, it should be considered speculative until it can be replicated in further studies.

\section{Conclusions}

Our findings indicate that two personality characteristics having to do with habitual attention to behavioral tendencies, emotions, and motivations, significantly influence the quality of close heterosexual relationships. Private self-consciousness seems to enhance relationships by helping to provide a deeper and clearer knowledge of one's private self-aspects through self-disclosure, whereas perspective taking seems to help by reducing some of the tension produced by the psychological proximity of two different points of view. When relationship problems occur, they may result from deficits in either awareness of oneself (private self-consciousness) or awareness of others (perspective taking). These results extend our current understanding of the impact that 
personality characteristics have on the nature and quality of intimate relationships. The next step in this research vein should be to investigate the dynamics of these variables over time in order to more accurately chart the causal chain suggested by the present analyses.

\section{Footnotes}

${ }^{1}$ For both male and female subjects, the predominant response to this item was the "mutual give-and-take" response. Seventy-two percent of male subjects and $73 \%$ of female subjects reported that their disagreements were usually settled in this fashion. When the procedure just described was used to assign a score to the couple, $16 \%$ of the couples received a score of $0,26 \%$ received a score of 0.5 , and the remaining $58 \%$ received a score of 1.0 .

${ }^{2}$ The correlation between partners' self-disclosure tendencies was low $(r=.19, p<.05)$, indicating that reciprocal self-disclosure was not a strong norm in these relationships. Although the self-disclosure relation was weak, there was a substantial correlation in partners' feelings of satisfaction in the relationship $(r=.53, p$ $<.001)$.

\section{References}

Berg, J. H., \& Peplau, L. A. (1982). Loneliness: The relationship of self-disclosure and androgyny. Personality and Social Psychology Bulletin, 8, 624-630.

Bernstein, W. H., \& Davis, M. H. (1982). Perspective-taking, self-consciousness, and accuracy in person perception. Basic and Applied Social Psychology, 3, 1-19.

Burke, R. J., Weir, T., \& Harrison, D. (1976). Disclosure of problems and tensions experienced by marital partners. Psychological Reports, 38, 531-542.

Burr, W. R. (1970). Satisfaction with various aspects of marriage over the life cycle: A random middle class sample. Journal of Marriage and the Family, 32, 29-37.

Chelune, G. J., Sultan, F. G., \& Williams, C. L. (1980). Loneliness, self-disclosure, and interpersonal effectiveness. Journal of Counseling Psychology, 27, 462-468.

Cohen, J., \& Cohen, P. (1975). Applied multiple regression/correlation analysis for the behavioral sciences. New York: Wiley.

Davis, M. H. (1980). A multidimensional approach to individual differences in empathy. JSAS Catalog of Selected Documents in Psychology, 10, 85.

Davis, M. H. (1983). Measuring individual differences in empathy: Evidence for a multidimensional approach. Journal of Personality and Social Psychology, 44, 113-126.

Derlega, V. J., \& Grzelak, J. (1979). Appropriateness of self-disclosure. In G.Chelune (Ed.), Self-disclosure: Origins, patterns, and implications of openness in interpersonal relationships. San Francisco: Jossey-Bass.

Fenigstein, A., Scheier, M. F., \& Buss, A. H. (1975). Public and private self-consciousness: Assessment and theory. Journal of Consulting and Clinical Psychology, 43, 522-528.

Franzoi, S. L. (1983). Self-concept differences as a function of private self-consciousness and social anxiety. Journal of Research in Personality, 17, 275-287.

Franzoi, S. L., \& Brewer, L. C. (1984). The experience of self-awareness and its relation to level of selfconsciousness: An experiential sampling study. Journal of Research in Personality, 18, 522-540.

Franzoi, S. L., \& Davis, M. H. (1985). Adolescent self-disclosure and loneliness: Private self-consciousness and parental influences. Journal of Personality and Social Psychology, 48, 764-776.

Glass, S. P., \& Wright, T. L. (1977). The relationship of extramarital sex, length of marriage, and sex differences on marital satisfaction and romanticism: Athanasiou's data reanalyzed. Journal of Marriage and the Family, 39, 691-703.

Jourard, S. M. (1971). The transparent self. New York: Van Nostrand. 
Levinger, G., \& Senn, D. J. (1967). Disclosure of feelings in marriage. Merrill Palmer Quarterly, 13, 237-249.

Locke, H. J. (1951). Predicting adjustment in marriage: A comparison of a divorced and a happily married group. New York: Holt.

Luckey, E. B. (1966). Number of years married as related to personality perception and marital satisfaction. Journal of Marriage and the Family, 28, 44-48.

Mead, G. H. (1934). Mind, self, and society. Chicago: University of Chicago Press.

Miller, L. C., Berg, J. H., \& Archer, R. L. (1983). Openers: Individuals who elicit intimate self-disclosure. Journal of Personality and Social Psychology, 44, 1234-1244.

Neale, M. A., \& Bazerman, M. H. (1983). The role of perspective-taking ability in negotiating under different forms of arbitration. Industrial and Labor Relations Review, 36, 378-388.

Parsons, T., \& Bales, R. F. (1955). Family socialization and interaction process. New York: Free Press of Glencoe. Piaget, J. (1932). The moral judgment of the child. (M. Gabain, trans.). New York: Harcourt, Brace and World. Scheier, M. R., Buss, A. H., \& Buss, D. M. (1978). Self-consciousness, self-report of aggressiveness, and aggression. Journal of Research in Personality, 12, 133-140.

Solano, C. H., Batten, P. G., \& Parish, E. A. (1982). Loneliness and patterns of self-disclosure. Journal of Personality and Social Psychology, 43, 524-531.

Turner, R. G. (1978a). Consistency, self-consciousness, and the predictive validity of typical and maximal personality measures. Journal of Research in Personality, 12, 117-132.

Turner, R. H. (1978b). The role and the person. American Journal of Sociology, 84, 1-23.

Submitted: August 5, 1983 Revised: January 26, 1984 